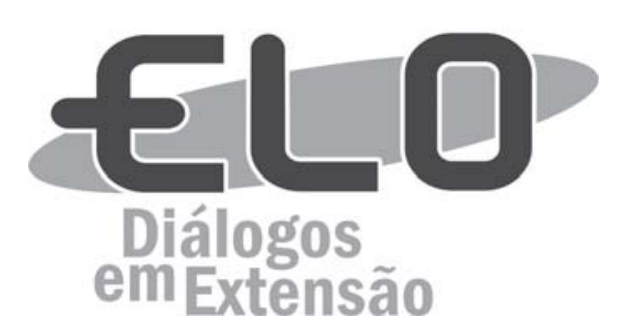

\title{
O principio da indissociabilidade entre ensino, pesquisa e extensão como paradigma de uma universidade socialmente referenciada
}

\author{
Larissa Dalcin ${ }^{1}$, Rudinei Barichello Augusti ${ }^{2}$
}

\begin{abstract}
Resumo: Este texto destina-se a fazer uma análise do princípio da indissociabilidade entre ensino, pesquisa e extensão apontados como um paradigma de uma universidade socialmente referenciada, buscando nesse sentido um diálogo crítico a partir do qual vem sendo constituída a universidade, suas possibilidades e limites. O mesmo descreve, analisa, sintetiza e está aberto à posteriores discussões. Primeiro, busca refletir a construção histórica da Universidade; em segundo, faz uma abordagem da Universidade enquanto campo epistêmico, situando o Ensino e a Pesquisa como indissociáveis tecendo a universidade a partir do elemento universalidade do saber e do conhecimento; em terceiro, discute e apresenta o princípio da indissociabilidade entre Ensino, Pesquisa e Extensão; por último, apresenta as abordagens legais, didáticas e metodológicas da indissociabilidade entre Ensino, Pesquisa e Extensão no cenário da Universidade de hoje.
\end{abstract}

Palavras-chave: Indissociabilidade. Universidade Socialmente Referenciada. Diálogo Crítico. Universidade. Área Temática: Educação.

The principle of indivisibility of teaching, research and extension as a paradigm of a socially relevant university

Abstract: This text is intended to make an analysis of the principle of indivisibility of teaching, research and extension identified as a paradigm of a socially relevant university, seeking in this sense a critical dialogue from which has been made the university, its possibilities and limits. The same describes, analyzes, synthesizes and is open to further discussions. First, it seeks to reflect the historical construction of the University; second, is an approach the University as epistemic field, situating Education and Research as inseparable weaving the university from the element of universal wisdom and knowledge; third, discusses and presents the principle of indivisibility of Education and Research; Finally, it presents the legal, educational and methodological approaches of the inseparability of Education and Research in the scenario of the University today.

Keywords: Indissociabilidade. University Socially Referenced. Critical Dialogue. University.

\section{El principio de la indivisibilidad de la enseñanza, la investigación y la extensión como paradigma de una universidad socialmente referida}

Resumen: Este texto está destinado a realizar un análisis del principio de la indivisibilidad de la enseñanza, la investigación y la extensión identificada como paradigma de una universidad socialmente relevante, buscando en este sentido un diálogo crítico a partir del cual se ha hecho la universidad, sus posibilidades y sus límites. El mismo describe, analiza, sintetiza y está abierto a nuevos debates. En primer lugar, se busca reflejar la

\footnotetext{
${ }^{1}$ Psicóloga. Mestra em Psicologia pela PUCRS - Pontifícia Universidade Católica do Rio Grande do Sul - 2016. Doutoranda em Educação nas Ciências pela UNIJUÍ - Universidade Regional do Noroeste do Estado do Rio Grande do Sul - 2016. Avenida Dom Pedro II, 2295, apto 302, Centro, Santo Cristo - RS. Fone: (55) 996926432 98960-000. E-mail: lddalcin@gmail.com

${ }^{2}$ Licenciado em Filosofia pela UNIJUI - Universidade Regional do Noroeste do Estado do RS - 2003. Mestre em Educação nas Ciências pela UNIJUÍ - Universidade Regional do Noroeste do Estado do RS - 2009. Doutorando em Educação nas Ciências pela UNIJUÍ - Universidade Regional do Noroeste do Estado do Rio Grande do Sul - 2016. Endereço: Rua Horizontina, 1372, apto 302 - Três de Maio - RS. 98910-000. Fone: (55) 99622-4493. E-mail: rudinei.augusti@gmail.com
} 
construcción histórica de la Universidad; En segundo lugar, es una aproximación de la Universidad como campo epistémico, situando Educación e Investigación como inseparables tejiendo la universidad desde el elemento de la sabiduría universal y el conocimiento; En tercer lugar, se analiza y presenta el principio de indivisibilidad de Educación e Investigación; Finalmente, se presentan los enfoques jurídicos, educativos y metodológicos de la inseparabilidad de Educación e Investigación en el escenario actual de la Universidad.

Palabras clave: Indisociabilidad. Universidad Socialmente Referida. El diálogo crítico. Universidad.

\section{Introdução}

A educação pode ser considerada como uma das condições básicas pelas quais o sujeito desenvolverá suas capacidades ontológicas essenciais e é papel do processo educativo atual a humanização plena do ser humano, principalmente no que se refere à concretização dessas propriedades (SANTOS, 2010).

Para esse autor, o termo universidade apresenta-se conectado a muitos outros, tais como ciência, autonomia, pesquisa, ensino superior, entre outros, que não podem ser compreendidos de forma isolada. No entanto, o autor questiona se as suas finalidades e ideais, que foram tradicionalmente aceitos, ainda são, ou seja, permanecem válidos atualmente.

De acordo com Chauí (2001, p.216), a universidade brasileira nos dias atuais é:

Uma instituição social que aspira à universalidade e que tem a sociedade como seu princípio e sua referência normativa e valorativa, a qual se percebe inserida na divisão social e política e busca definir uma universalidade (imaginada ou desejada) que lhe permita responder às contradições impostas por esta divisão. Logo, a universidade é um devenir, uma construção constante que está amparada numa concepção de possibilidade de destruir os fins capitalistas pelo que até agora ela atuou e de construir uma nova história como resultante de ações de seres humanos conscientes.

A partir dos escritos de Chauí (2001), pode-se verificar que a missão da universidade só parece ser legitimada se esta estiver envolvida com as reais necessidades aspirações da sociedade, a qual deve servir. Nesse sentido, percebe-se que a universidade como está estruturada produz conhecimento, que gera pesquisas a partir das interrogações nas quais surgirão novas ideias. Essa transmissão de saberes denomina-se ensino.

No entanto, somente nos anos 60 , período no qual as instituições de ensino superior começaram a discutir a questão da práxis universitária é que o conceito destas instituições começou a ser entendido atrelado ao ensino-pesquisa-extensão. Nesse sentido, a extensão constitui um processo metodológico, o qual pergunta sobre a relevância do ensino e busca por meio da pesquisa, referências para os problemas reais que podem ser visualizados na sociedade. Ainda, pode-se refletir que a extensão universitária, é uma forma de interação que deve existir entre a universidade, seja ela pública ou privada e a comunidade em geral (SANTO, 2010).

A universidade é a detentora do conhecimento, nesse sentido, entendido como formal científico e esta irá transmiti-lo para os educandos por meio do ensino. Para além, por intermédio da pesquisa, esses conhecimentos serão aprimorados e consequentemente, surgirão outros, novos, que por meio da extensão serão difundidos, socializados e democratizados, bem como, será uma forma de levar novas descobertas à comunidade. Portanto, esse artigo tem por objetivo fazer uma análise do princípio da indissociabilidade entre ensino, pesquisa e extensão apontadas como um paradigma de uma universidade socialmente referenciada, buscando nesse sentido um diálogo crítico a partir do qual vem sendo constituída a universidade, suas possibilidades e limites.

\section{A Universidade - Breve Percurso Histórico}

$\mathrm{Na}$ Antiguidade greco-latina clássica se construíram as primeiras escolas superiores. Já na antiguidade clássica, encontramos a Escola de Pitágoras, a Academia de Platão, o Liceu de Aristóteles e a Escola de Alexandria. 
Na Idade Média, a partir do desenvolvimento da Escolástica, surge a Universidade como lugar onde se cultiva o amor pelas letras e pelas artes. Elas estavam sob controle das ordens monásticas, entre os quais se destacavam os monastérios beneditinos. A prática monástica era sublinhada pelo trabalho manual e a oração comunitária. Somente participavam da educação nos monastérios os filhos dos barões e da nobreza. Carlos Magno fundou a escola palatina de caráter secular junto à sua corte, em um período também conhecido como Império Carolíngio. Nessa escola, se ensinavam a doutrina religiosa, a cultura e as artes liberais, a gramática, retórica, dialética, aritmética, geometria, astronomia e música.

Na Idade Média, em especial o Século XIII, é considerado o Século das Universidades. Os intelectuais, seguindo o espírito das corporações daquela época, também assim se organizaram. As universidades lutavam contra interesses políticos e religiosos, em que muitas vezes, saiam vitoriosas, até com certos privilégios como a autonomia. A Universidade nesse período, tinha quatro faculdades: Artes, Direito, Medicina e Teologia. A mesma outorgava título de graduado, mestre e doutor.

Os métodos de ensino universitário se reduziam à três: leitura, a questão e a discussão. A educação universitária era unicamente livresca, sendo que era realizada uma seleção muito limitada de livros sobre cada campo, os quais eram aceitos de forma absoluta e verdadeira. Portanto, a universidade era pautada no domínio dos discursos formais e argumentação, e não para a aquisição do conhecimento e/ou busca da verdade (MONROE, 1979).

As principais Universidades desse tempo foram a Universidade de Bolonha (1.119), Universidade de Oxford (1.167), Universidade de Paris (1.170), Universidade de Cambridge (1.209), Universidade de Nápoles (1.224), entre outras, que até o ano de 1.400 somavam quarenta e quatro Universidades. Trinta e uma dessas universidades outorgavam títulos autorizados pela Igreja Cristã. Assim, fica evidente que a grande contribuição da Igreja na Idade Média, foi a crescente criação de Universidades (MONROE, 1979).

O que se percebe até então, é que a Universidade após seu surgimento, busca por meio da Escolástica Medieval, espalhar-se por toda a Europa, e mais tarde, pelo mundo. Desde o seu surgimento, esta instituição sempre cultivou e transmitiu o saber humano que era acumulado, e que portanto, desempenhava um importante papel social (WANDERLEY, 2003).

Na América, foram fundadas mais de trinta Instituições de Ensino Superior do ano 1538 até o ano de 1812. A primeira Universidade que se tem conhecimento na América, foi a Universidade de Santo Domingo, dirigida pelo Papa de então, Paulo III. No mesmo século, o sistema universitário espanhol chega para a América Latina. No Brasil, nesse momento, a educação superior era influenciada por Portugal e Espanha, e portanto era destinada para a elite dos países latinos (ROSSATO, 2005).

No Brasil, o Ensino Superior tem seu início em 1808 com a vinda de Dom João VI. Esse movimento se deu a partir do momento em que a corte portuguesa, chegando ao Brasil, sentiu a necessidade de fundar as primeiras escolas superiores. Nesse tempo, os estudos superiores estavam destinados exclusivamente ao clero. A preocupação central da criação dessas escolas superiores estava em criar uma infraestrutura que garantisse a cultura da Corte na Colônia, uma vez que a criação dessas escolas era de iniciativa da própria Corte. Mesmo com todo esforço da Corte, os primeiros cursos de ensino jurídico do Brasil foram criados e desenvolvidos após a Independência, em meados dos anos de 1827, em São Paulo e Olinda.

\footnotetext{
Os idealizadores da educação Superior para o Brasil prosseguiram em seus esforços durante 300 anos após o descobrimento, mas os interesses da Coroa Portuguesa, sempre foram claros em sentido contrário e, na maioria das vezes, o governo contou com o apoio decisivo da Igreja de Roma para exercer seu poder cerceador. (FINGER, 1988, p.6)
}

Sobre essa perspectiva, Cristovam Buarque afirma que "cem anos depois da Independência e trinta e três depois da Proclamação da República, o Brasil ainda não possuía uma Universidade e, ela só foi criada para atender as conveniências de um rei europeu. (BUARQUE, 2003, p.21).

A partir de 1922, com a Semana da Arte Moderna no Brasil, tem início um grande movimento de modernização do país. A Semana da Arte Moderna representou para o Brasil um movimento pela 
independência artística e, porque não dizer, pela independência intelectual. Soma-se a esse movimento que impregnava em todos os cantos do Brasil um cenário de transformação cultural e econômica, o movimento da Escola Nova que tinha como bandeira a Escola Pública, Laica e gratuita. O movimento da Escola Nova, foi impulsionada pelos pioneiros da educação nova, Fernando de Azevedo, Anísio Teixeira, Cecília Meirelles, Paschoal Lemme, entre outros, que manifestaram o desejo da Educação Pública por intermédio do Manifesto dos Pioneiros da Educação Nova de 1932.

Porém, em 1931 o sistema de Educação Superior do país é reorganizado. Nesse ano, o Brasil estava vivendo uma profunda reforma educacional liderada pelo ministro da educação e saúde Francisco Campos. A partir dessa reforma nasce a primeira universidade Brasileira em 1934 - a USP - Universidade de São Paulo. Inspirada na Reforma Educacional, também em 1935, cria-se a Universidade do Distrito Federal.

A partir desse momento, muitos são os movimentos decorrentes da proposta e da intervenção acadêmico-social da universidade no Brasil: participação dos estudantes em greves e lutas nos movimentos sociais, a gestão democrática dos Diretórios estudantis na busca de melhores condições e qualidade do Ensino, marcha dos estudantes durante o período da Ditadura Militar, a Reforma Universitária em 1968, a luta pelos direitos iguais e universidade para todos, entre outras. Diante de todo processo, ainda hoje é bandeira de luta nas universidades no Século XXI, um ensino público, laico, de qualidade, gratuito e que garanta a inclusão de todos, independentemente da condição social, econômica e de etnia.

\section{Compreendendo a Universidade como campo epistêmico}

A palavra "Universidade", em sua origem etimológica, advém do latim Universitas, formado pelo adjetivo Universus-a-um que significa todo, inteiro, universal. Esta palavra derivada do latim, quando de sua utilização, considera em seu aspecto de coletividade a denotação de um corpo dedicado ao ensino; mas não só, à necessidade de uma adição que venha a complementar o seu sentido/ significado: "Universitas Magistrorum et Scholarium" (coletivo de mestres e de estudantes) (REZENDE, 2014, p.453)

A partir do esboço histórico apresentado acima, mesmo que de forma rápida, percebe-se que a universidade tem desempenhado papéis fundamentais quando se trata de pensar o desenvolvimento da sociedade, no que se refere à evolução da ciência, dos aspectos tecnológicos, políticos, culturais. Em diferentes tempos, a universidade esteve a serviço de diferentes ideologias econômicas, entre outros desafios que fazem parte de seu lócus social.

Enquanto princípio epistemológico, a Universidade se propõe a produzir conhecimento. Esse princípio se dá pelo viés da procura de mecanismos que introduzam a tecnologia nos espaços acadêmicos, a inserção de estudos bibliográficos que conduzem à reflexão filosófica, o fomento artístico. Assim, o domínio da ciência, tecnologia e cultura são os primeiros objetivos. A partir desses princípios, decorre a educação dos jovens para que exerçam a vida profissional de maneira integral. A partir da compreensão do acúmulo cultural de conhecimentos, a universidade desenvolve por meio da pesquisa as interrogações em torno da produção de novas ideias.

À transmissão desses saberes acumulados na Universidade, dá-se o nome de ensino. O mesmo se desenvolve em um ambiente com os instrumentos e, sobretudo, os fins adequados a essa proposta. O Ensino sem a pesquisa é estéril. É apenas um ensino livresco, rotineiro e sem vitalidade, onde se repetem de forma monótona o que outros autores fizeram ou escreveram.

Nesse rol das compreensões epistemológicas do ensino, possibilita-se pensar a docência enquanto espaço do desenvolvimento de atividades baseadas na pesquisa e na dinâmica do ensino-aprendizagem. Sobre esse aspecto, é importante observar que o ato da docência não se dá de forma isolada e neutra, pois responde às condições históricas, políticas e sociais, bem como o estágio de desenvolvimento das políticas públicas e da estruturação da própria universidade.

Mas, se tal produção responde sempre a necessidades é importante não esquecer, também, que esse conhecimento não se dá nem se produz de forma neutra, distante e fria; está profundamente enraizado na vida dos homens, em determinado momento histórico. (FÁVERO, 2003, p. 254) 
Pelo até aqui exposto, fica evidente que, em primeiro lugar, a Universidade se propõe à investigação por intermédio da pesquisa para a produção de conhecimento. Em segundo, necessariamente, a transmissão desse saber. Tanto a pesquisa quanto o ensino buscam desenvolver as habilidades acadêmicas e as competências profissionais necessárias para a formação de profissionais aptos a desenvolver contribuições para os conhecimentos das diferentes áreas do saber, bem como colaborar para o desenvolvimento dos locais e regiões de suas inserções.

É papel da Universidade no âmbito do saber, garantir aos estudantes, no seu processo de comunicação científica, um conhecimento aprofundado, interdisciplinar e politicamente responsável. Nesse sentido, aquém de uma formação científica global, corre o risco de o estudante garantir sua profundidade científica e uma determinada especialidade; ou seja, tornar-se um especialista fragmentado em seu saber. Por isso, toda atividade de formação por meio do ensino, não pode desmerecer a pesquisa como forma de aprofundar os saberes que o compõe.

Assim, quanto às abordagens epistêmicas da Universidade, fundam-se prioritariamente em duas abordagens:

1) A pesquisa como possibilidade do novo. Dado o acumulo de saberes historicamente construídos e sistematizados na Universidade, a pesquisa, por intermédio das especulações filosóficas em diferentes campos/áreas do saber investiga e sistematiza os novos saberes que constituem a dinâmica curricular, sempre em constante processo de atualização.

2) Formação política de cidadãos. Além da especialização em determinadas áreas da ciência, tecnologia, humanidades, por meio do conhecimento acumulado, a reflexão política sobre a ciência e a tecnologia, bem como a realização das abordagens críticas sobre os problemas sociais, étnicos, culturais, artísticos, filosóficos e científicos.

Assim, o conhecimento na/da Universidade ultrapassa a dimensão restrita das relações sociais que os indivíduos tecem no cotidiano. Sua epistemologia não é tão somente matéria prima do desenvolvimento econômico, há outros significados que a compõem no aspecto social. O conhecimento da universidade é essencial para a formação e corresponsabilidade dos mesmos na construção de uma sociedade melhor. Nesse sentido, para além do contributo individual e coletivo bem como a correlação com a sociedade, a Universidade faz parte do conteúdo e da necessidade do elemento humanidade, onde os saberes e as técnicas precisam estar imbuídos de rigor científico, pertinentes ao acadêmico e de impacto social nas coletividades. Assim, a epistemologia da universidade se insere em seu sentido político.

Percebendo os movimentos críticos na atualidade no âmbito do saber e dos questionamentos que se fazem em torno dos mesmos, percebe-se que a Universidade atual está solidificada à burocracia e a necessidade de uma produtividade aniquiladora dos processos criativos. Em nome do produtivismo acadêmico, anula-se o ético e o moral como princípios cidadãos e surge em meio a essa crise, o indivíduo como homo economicus. A formação do mesmo ocorre reduzida ao sistema econômico.

Esta realidade predominante nas universidades, desloca o foco da preocupação das Universidades com questões como a liberdade, a crítica e a reflexão. Isso se intensifica quando a universidade não reflete sobre si mesma. Dessa forma, os grandes problemas da humanidade não fazem mais parte do imaginário crítico da Universidade, ou seja, dos processos de ensino-aprendizagem e da construção de conhecimento no âmbito da ação comunicativa dos indivíduos. Marcada historicamente pela preocupação com a construção do conhecimento, relações interpessoais, as incertezas políticas, os debates críticos, a pluralidade e os questionamentos, a universidade de hoje abre mão dessa dinâmica que por hora contribuíam para o desenvolvimento humano e científico e promoviam ações para a envergadura da justiça, para apoiar o crescente interesse do capital econômico sobre o saber.

Dessa forma, a abordagem epistêmica da Universidade de hoje abdica de reflexões que a acompanharam e garantiram sua legitimidade, para associar-se às proposições de uma formação neoliberal e operacional que não colabora para a inserção do sujeito na dinâmica da vida política e pública. Nesse sentido, o saber epistemológico da universidade, servindo aos objetivos da expansão da esfera privada sobre a economia, contribui para a ampliação e potencialização da desigualdade social, restringindo o acadêmico à condição de consumidor, e o saber, à condição de produto a ser comercializado.

Esse modelo epistêmico de universidade, diga-se, comprometido com a consolidação ideológica da estrutura política e economia neoliberal, pensa a ciência e a tecnologia a partir do progresso material da sociedade. Diante disso, a Universidade não pode acovardar-se de sua função original: a construção 
de uma sociedade mais equitativa, potencializando a ciência e a tecnologia bem como o rol de saberes universitários na direção do combate à desigualdade social, pobreza, etc., em outras palavras, por intermédio do seu lócus epistemológico protagonizar o exercício cidadão e consciente dos direitos que compõe a esfera global dos indivíduos: civis, políticos, econômicos, sociais, culturais.

Assim, a perspectiva epistemológica da Universidade requer uma reconstrução imediata que seja capaz de responder às comyplexas exigências e desafios que atravessam as contradições sociais e seus dissensos. A essência da Universidade, seu saber, não está isento de discórdias e preocupações que dizem respeito às questões de seus fins, mas apontam para o que realmente essas questões significam, ou seja, pensar quais são as concepções de educação e quais os objetivos da Universidade enquanto protagonista de saberes validados e legitimados socialmente.

Dessa forma, a universidade em sua perspectiva epistêmica tem como lócus o fato humano, decorrente da ação humana em todas as suas dimensões; ou seja, o homem como produtor e resultado dos processos antagônicos de sua inserção na construção histórica, bem como, enquanto sentido teórico, é articulador das totalidades do seu existir.

Está em sua tematização o pleno exercício das representações sincronizadas e diacronizadas da sociedade humana. Percebe-se a presente abordagem quando da tematização e a interferência da Universidade no sentido do universal: ao mesmo tempo que visualiza também busca o seu sentido. Nesse ínterim, se faz a Universidade em sua dinâmica de ser, estar, existir.

\section{O princípio da Indissociabilidade entre Ensino, Pesquisa e Extensão}

A discussão que gira em torno dos pressupostos da indissociabilidade entre Ensino, Pesquisa e Extensão busca a ressignificação de toda ação universitária perseguir o princípio vinculado ao processo de formação de pessoas e de geração de conhecimento. A preocupação na difícil tarefa do fazer-se universidade volta-se para o anseio da realização da tarefa da promoção da totalidade no que se refere ao Ensino, Pesquisa e Extensão em uma abordagem de universalidade.

No entanto, com as transformações ocorridas no cerne da questão ideológica da Universidade, quando a mesma se propõe por meio do abandono ou do uso da reflexão universitária, agora pautada na especialização e fragmentação do conhecimento e do saber universitário, assume uma postura hegemônica politica e epistemologicamente liberal em seu sentido de mantença, é então necessário pautar-se que a reforma na universidade deve partir da desconstrução das formas hegemônicas de poder e direcionar-se para a questão da legitimidade que só é possível na dinâmica da indissociabilidade.

As reformas devem partir do pressuposto que no Século XXI só há universidade quando há formação graduada e pós-graduada, pesquisa e extensão. Sem qualquer destes, há ensino superior, não há universidade. Isto significa que, em muitos países, a esmagadora maioria das universidades privadas e mesmo parte das universidades públicas não são universidades porque lhes falta a pesquisa ou a pós-graduação. (SANTOS, 2011, p.65)

Além da importância da redefinição da Universidade no sentido conceitual, o que lhe mantém protegida do sistema predatório social que passa por práticas de consumo e mercado legitimados pela exploração do capital, a luta por sua legitimidade, aborda, segundo SANTOS (2011, p.65) a garantia de "o acesso; extensão; pesquisa-ação; ecologia dos saberes; universidade e escola pública".

Dentro da abordagem de discussão desse artigo, que busca compreender a indissociabilidade do Ensino, Pesquisa e Extensão na Universidade, o debate segue a partir da Extensão como modo alternativo ao capitalismo global; as ações em extensão, bem como o objetivo prioritário da Extensão.

Como modo alternativo ao capitalismo global, a extensão remete ao pensar que resinifica a Universidade a partir de sua participação ativa na construção do debate social. O capitalismo global vem, em sua dinâmica assertiva de mercado internacionalizado, supondo a pretensa vontade de transformar a universidade em ferramenta ideológica à seu serviço. Não é apenas um movimento de ressignificação no âmbito estrutural e funcional, mas implica em um posicionamento epistemológico que confere poder em relação ao "aprofundamento da democracia, na luta contra a exclusão social e a degradação ambiental e, na defesa da diversidade cultural" (SANTOS, 2011, p. 73). Em outras palavras, essa ressignificação passa também pela discussão dos currículos e na formação dos docentes. 
“No momento em que o capitalismo global pretende funcionalizar a Universidade e, de fato, transformá-la numa vasta agência de extensão ao seu serviço, a reforma da universidade deve conferir uma nova centralidade às atividades de extensão". (SANTOS, 2011, p. 73)

Tendo presente o sentido da Universidade enquanto universalidade do saber a partir do paradigma de uma universidade socialmente referenciada, a Extensão por intermédio da dinâmica de um processo de interação dialógica, aproximando a universidade dos outros setores sociais, implica o diálogo, a troca de saberes, a superação do discurso hegemônico acadêmico ${ }^{3}$, visando o estabelecimento de relações dialéticas com movimentos sociais superando a desigualdade e a exclusão social.

As ações de extensão na universidade não se limitam à área de prestação de serviços, mas se voltam para o desenvolvimento do protagonismo em diferentes grupos sociais.

\begin{abstract}
“A extensão envolve uma vasta área de prestação de serviços e os seus destinatários são variados: grupos sociais populares e suas organizações; movimentos sociais; comunidades locais ou regionais; governos locais; o setor público; o setor privado. Para além dos serviços prestados a destinatários bem definidos, há também toda uma outra área de prestação de serviços que tem a sociedade em geral como destinatária. A título de exemplo: "incubação" da inovação; promoção da cultura científica e técnica; atividades culturais no domínio das artes e da literatura." (SANTOS, 2011, p. 73-74)
\end{abstract}

Assim, a relação que se estabelece entre Universidade e os outros setores da sociedade se dá com vistas à uma atuação transformadora, ou seja, o processo dialógico ancora-se na dialética como relação da teoria e prática. Quanto aos princípios da transformação dos grupos e, porque não dizer, da própria universidade, a ação mediada pela crítica possibilita o desenvolvimento e implementação de políticas públicas que tratem do desenvolvimento regional.

É importante observar também, que o solo em que se dá a ação da extensão é complexo, uma vez que implica no reconhecimento da diversidade de realidades. Sobre essa premissa, a que se concordar de que, dada a caracterização e abrangência das ações em extensão, é fator desafiante para a universidade colaborar efetivamente para a mudança social. Por essa questão, mais que desenvolver ações de extensão no contexto citado, é necessário desenvolver o movimento dialético (crítica ao dualismo teoria versus prática), em todos os seus detalhes, evidenciando o estudo em grupos autorreflexivos que gestem o ensino e a pesquisa em um processo de detalhamento, discussão, produção, publicações, declarando na indissociabilidade o compromisso do curriculum profissional dos docentes bem como a dimensão política da universidade no sentido da atuação para a mudança social.

A partir da discussão da extensão como modelo alternativo ao capitalismo global, problematizado pela dimensão estruturante da universidade mercadológica/mercantil; das ações em extensão, agora é necessário discutir a extensão a partir de seu objetivo prioritário. Para tanto, compreende-se como extensão: "A Extensão universitária é um processo educativo, cultural e científico que articula o Ensino e a Pesquisa de forma indissociável e viabiliza a relação transformadora entre a Universidade e a Sociedade" (FORPROEX, 2007, p. 17).

Dado o desafio da Extensão na Universidade ser um processo educativo, cultural e científico, articulado por meio dos processos de Ensino e Pesquisa, ela acontece na afirmação de que Extensão é um processo da Universidade enquanto sentido de sua existência, onde a mesma se dá em sua compreensão democrática, quando do "apoio solidário da resolução de problemas de exclusão e discriminação social e de tal modo que nele se dê voz aos grupos excluídos e discriminados" (SANTOS, 2001, p. 74). Fica evidente que, a partir da descrição do objetivo prioritário da extensão, haja com urgência a reestruturação da Universidade, seja enquanto aspectos conceituais, de gestão, ou mesmo de fins.

Discutiu-se dessa forma, o princípio da indissociabilidade do Ensino, Pesquisa e Extensão na Universidade, pelo mote da afirmação da extensão como processo de produção de conhecimento vinculado à necessidade de formação de agentes para a transformação social. Nesse último, a necessidade acadêmica de assumir uma postura no Ensino e na Pesquisa que norteie o compromisso 
da universidade para com as políticas públicas, contribuindo para a implementação e o reconhecimento da Universidade como um espaço socialmente referenciado.

\section{Abordagens Legais, Didáticas e Metodológicas da Indissociabilidade Ensino, Pesquisa e Extensão}

Ainda que a indissociabilidade Ensino, Pesquisa e Extensão mereçam uma abordagem descritiva e reflexiva em seus aspectos legais, no sentido das diretrizes em educação, observa-se que a mesma atende às necessidades do processo de reconceituação da universidade nos tempos atuais. Ao situar a reconceituação da Universidade nos aspectos já descritos anteriormente, observa-se que toda inclinação de reconceituação, inclusive a da própria extensão, implica no reconhecimento da transição do paradigma moderno da universidade (modelo de racionalidade técnica, que oferece uma visão fragmentada de mundo), tendo em vista a abordagem da construção de um novo paradigma, assentado na perspectiva intersubjetiva (racionalidade dialética) que assume a mediação da universidade com os sujeitos sociais por intermédio do diálogo crítico nas comunidades de autorreflexão, bem como a construção de uma visão complexa de mundo.

Portanto, esse movimento inicia-se com o Movimento de Reforma Universitária de 1968, por meio da Lei Básica da Reforma Universitária - N. ${ }^{\circ} 5.540$ de 1968 que instituía em seu Art. 20: “As universidades e as instituições de Ensino Superior atenderão à comunidade, sob a forma de cursos e serviços especiais, as atividades de ensino e os resultados da pesquisa que lhe serão inerentes". Doravante, em seu Art. 40, a mesma lei apresentava o seu desenvolvimento pedagógico afirmando de que “a) Por meio de suas atividades de extensão, proporcionarão aos seus corpos discentes oportunidades de participação em programas de melhoria das condições de vida da comunidade e no processo geral de desenvolvimento."

A partir desse movimento da Reforma Universitária de 1968, fica implícito uma visão assistencialista do sentido da extensão na Universidade. Mas, desde já, sugere o Art. 40, uma orientação quanto das finalidades da extensão, por intermédio de programas que possibilitem qualificar o social em seu lócus de desenvolvimento bem como atentem para a melhoria da qualidade de vida das pessoas neles envolvidas.

Na Constituição da República Federativa do Brasil de 1988, em seu Art. 207, em capítulo que trata especificamente das questões em educação, sugere que as universidades, em seu processo de gestão, tenham autonomia didático-científica, mas que obedeçam ao princípio da indissociabilidade do Ensino, Pesquisa e Extensão, fomentado por recursos públicos definidos em programas e leis.

Art. 207. As universidades gozam de autonomia didático-científica, administrativa e de gestão financeira e patrimonial, e obedecerão ao princípio de indissociabilidade entre ensino, pesquisa e extensão.

\section{[...]}

Art. 213. Os recursos públicos serão destinados às escolas públicas, podendo ser dirigidos a escolas comunitárias, confessionais ou filantrópicas, definidas em lei.

\section{$[\ldots]$}

$\S 2^{\circ}$ - As atividades universitárias de pesquisa e extensão poderão receber apoio financeiro do Poder Público. (BRASIL, 2014, s/p)

Por gozarem de autonomia didático-científica, as diferentes universidades também propõem diferentes abordagens pedagógicas quanto à compreensão de Extensão. No entanto, uma vez que a Educação Superior, respaldada pelo Art. 43 da Lei de Diretrizes e Bases da Educação Nacional - LDB 9.394/96, onde apresenta as finalidades da educação superior, propõe que a pesquisa, compreendida como investigação científica possa, por meio da ciência e da tecnologia, criar e difundir cultura, possibilitando ao homem em seu meio de vivências e trabalho, acessar as diferentes compreensões políticas de dada realidade (BRASIL, 1996).

A mesma Lei - LDB 9.394/96 propõe que, por intermédio do Ensino, ocorra a "divulgação de conhecimentos culturais, científicos e técnicos que constituem patrimônio da humanidade" (BRASIL, 
1996. s/p), bem como o mesmo seja uma forma de "comunicar o saber [...], de publicações ou de outras formas de comunicação"(BRASIL, 1996, s/p).

Na Lei de Diretrizes e Bases, em seu Art. 43, § VII, a Extensão é citada como aspecto democrático a partir de uma gestão democrática institucional, que visa a criação e a ampliação das conquistas das lutas sociais. Assim, compreende a finalidade da extensão como "Promover a extensão, aberta à participação da população, visando à difusão das conquistas e benefícios resultantes da criação cultural e da pesquisa científica e tecnológica geradas na instituição. (BRASIL, 1996, s/p)

Em seus aspectos metodológicos e pedagógicos, no âmbito do Ensino e Pesquisa, bem como da Extensão, a Lei de Diretrizes e Bases, em seu Art. 44, trata da educação superior em sua dinâmica didática e pedagógica de desenvolvimento, apresenta a indissociabilidade a partir das seguintes premissas:

“Art. $44^{\circ}$. A educação superior abrangerá os seguintes cursos e programas:

$[\ldots]$

II - de Graduação, abertos a candidatos que tenham concluído o Ensino Médio ou equivalente e tenham sido classificados em processo seletivo;

III - de Pós-graduação, compreendendo programas de mestrado e doutorado, cursos de especialização, aperfeiçoamento e outros, abertos a candidatos diplomados em cursos de graduação e que atendam às exigências das instituições de ensino;

IV - de Extensão, abertos a candidatos que atendam aos requisitos estabelecidos em cada caso pelas instituições de ensino. (BRASIL, 1996, s/p)"

Na compreensão das diferentes instituições de ensino, bem como dos requisitos quanto à extensão em cada uma delas, é importante observar que, a partir do Fórum dos Pró-reitores de Extensão FORPROEX, na dinâmica da organização e sistematização da Extensão na Universidade, define-se que os aspectos didáticos e metodológicos da extensão "são classificados em programa, projeto, curso, evento e prestação de serviços" (FORPROEX, 2007, p.35). Assim, define-se:

a) Programa: articulado a partir de um conjunto de projetos ou outras ações de extensão, onde se integram ensino, pesquisa e extensão. Orientados por um objetivo comum, se dá a partir da gestão institucional, bem como de suas diretrizes.

b) Projeto: de caráter educativo, social, cultural, científico e de objetivo específico. Pode ser vinculado à um programa de extensão ou não.

c) Curso: caráter teórico/prático, presencial ou a distância. Sua carga horária mínima reside em 8 horas e tem critérios de avaliação definidos.

d) Evento: Apresentação ou exibição pública sobre aspectos culturais, artísticos, esportivo, científico e tecnológico que seja reconhecido pela universidade.

e) Prestação de Serviço: Realização de serviços oferecidos pela Universidade e contratado por terceiros. Não se dá na separação do processo e produto. Não resulta da posse de um produto.

Quanto aos aspectos metodológicos e didáticos, enseja-se a necessidade de as propostas e desenvolvimento da extensão ampliarem-se na perspectiva interdisciplinar da indissociabilidade entre Ensino, Pesquisa e Extensão. Essa preocupação está disposta no Plano Nacional de Educação - 20142024, aprovado por lei (Aprovado LEI No 13.005, de 25 de Junho de 2014), em suas metas. É objetivo da meta 4.5, "estimular a criação de centros multidisciplinares de apoio, pesquisa e assessoria, articulados com instituições acadêmicas e integrados [...]" (BRASIL, 2014, s/p). Ainda, se percebe a necessidade de que as pesquisas interdisciplinares, realizadas a partir do desenvolvimento pedagógico e didático da indissociabilidade, disposto na meta 4.11 sirvam "para subsidiar a formulação de políticas públicas [...]" (BRASIL, 2014, s/p).

Para reforçar a necessidade da indissociabilidade Ensino, Pesquisa e Extensão no âmbito da universidade, vêm sendo discutido estratégias didáticas e metodológicas de integralização de créditos curriculares em programas e projetos de extensão, como se refere o Plano Nacional de Educação. 
“Meta 12.7. assegurar, no mínimo, dez por cento do total de créditos curriculares exigidos para a graduação em programas e projetos de extensão universitária, orientando sua ação, prioritariamente, para áreas de grande pertinência social." (BRASIL, 2014, s/p)

A implementação de no mínimo dez por cento do total de créditos curriculares exigidos para a graduação, com ênfase para áreas de grande pertinência social, deve envolver todos os setores da universidade, sejam eles discentes, docentes ou de gestão, uma vez que a integralização compreende a indissociabilidade como prática orgânica, o que opera na universidade o desafio do imobilismo pedagógico, partindo do estímulo e debate sobre as principais inquietações nas diferentes áreas de pertinência social, seja a nível local, regional e global.

$\mathrm{Na}$ ótica da indissociabilidade no sentido da integralização curricular, o debate não se isola na dimensão da extensão, mas perpassa o ensino e a pesquisa, pois compreende-se que, a existência do espaço constituído socialmente e epistemologicamente pelo discente, agora posto em pauta pela dinâmica da universidade, envolve os próprios estudantes em sua razão de saber, ser e existir.

“[...] saberes são conjuntos de práticas que promovem uma nova convivência ativa de saberes no pressuposto de que todos eles, incluindo o saber científico, se podem enriquecer nesse diálogo. Implica uma vasta gama de ações de valorização, tanto do conhecimento científico, como de outros conhecimento práticos, considerados úteis, cuja partilha por pesquisadores, estudantes e grupos de cidadãos serve de base à criação de comunidades epistêmicas mais amplas que convertem a universidade num espaço público de interconhecimento onde os cidadãos e os grupos sociais podem intervir sem ser exclusivamente na posição de aprendizes". (SANTOS, 2011, p. 77)

Outro aspecto que merece destaque no âmbito do Plano Nacional de Educação - PNE 2014-2024, está na dinâmica da criação de redes compreendidas aqui como espaços públicos que coletivamente reivindicam coletivamente benefícios, políticas e trocas de saberes, em que só algumas universidades se apropriam individualmente.

14.9. consolidar programas, projetos e ações que objetivem a internacionalização da pesquisa e da pós-graduação brasileiras, incentivando a atuação em rede e o fortalecimento de grupos de pesquisa públicas intersetoriais [...]

14.10. promover o intercâmbio científico e tecnológico, nacional e internacional, entre as instituições de ensino, pesquisa e extensão. (BRASIL, 2014, s/p)

Para desenvolver essas premissas, mais do que simplesmente discuti-las, é importante inserir nesse debate a legitimidade da universidade, assim como foi amplamente apresentado anteriormente. Em relação à rede de universidades, esse princípio é legitimador, uma vez que oferece não apenas a perda da hegemonia da universidade, mas o surgimento da heterogeneidade. No surgimento e na intensificação da heterogeneidade está o debate e a crítica que a longo prazo, do surgimento da universidade até os nossos dias vêm se tornando relevante: o debate e a crítica que se pode realizar com menos restrições em relação ao que é comum ao restante da sociedade. Esse princípio aponta para a (re)significação do bem público da universidade.

[...] proponho que o bem público da universidade passe a ser produzido em rede, o que significa que nenhum dos nós da rede pode assegurar por si qualquer das funções em que se traduz esse bem, seja ele na produção do conhecimento, a formação graduada e pósgraduada ou a extensão. Isto implica uma revolução institucional e uma revolução nas mentalidades". (SANTOS, 2011, P. 91-92) 
A rede amplia a necessidade da indissociabilidade entre Ensino, Pesquisa e Extensão na Universidade, pois há necessidade de se criar uma cultura baseada em três princípios básicos: densificar, democratizar e qualificar. Assim, a mesma acontece quando a reforma da universidade se dá pela via democrática possibilitando a desconstrução do mercantilismo universitário. Ao passo que se intensificam as redes, as relações de indissociabilidade também assim o fazem.

\begin{abstract}
“A teoria das redes fornece hoje pistas organizacionais preciosas. Podem ser multinível e multiescalares, devem fomentar a formação de nódulos e, em geral, promover o crescimento da multiconectividade entre as universidades, os centros de pesquisa e extensão, os programas de divulgação e publicação de conhecimento."(SANTOS, 2011, p.94-95)
\end{abstract}

De toda forma, toda legislação aqui apresentada é amplamente amparada por referenciais teóricos que se consolidam no debate sobre a Universidade. Por assim estar, a universidade é um bem público, espaço onde, em geral, a qualificação em termos de epistemologias é condição necessária para adentrar, sem rendição, em um universo de pluralidade de fatores: entre eles, a necessidade de compreender a indissociabilidade entre Ensino, Pesquisa e Extensão como paradigma de uma universidade socialmente referenciada.

\title{
Conclusões
}

A presente discussão apresentou uma análise do princípio da indissociabilidade entre ensino, pesquisa e extensão, que são apontadas como um paradigma de uma universidade socialmente referenciada, no qual buscou-se um diálogo crítico a partir do qual vem sendo constituída a universidade, suas possibilidades e limites. Por meio da análise realizada, pode-se perceber o quão importante apresenta-se o tripé ensino-pesquisa-extensão atualmente nas universidades.

No entanto, observa-se que com as transformações ocorridas no campo da educação, principalmente no que diz respeito à questão ideológica da Universidade, é preciso pautar-se em uma reforma destas instituições, reforma esta que deve partir da desconstrução do poder, nesse sentido, hegemônico, e direcionar-se a questão da legitimidade, que não pode ser entendida e nem construída sem pensar na dinâmica da indissociabilidade.

Para que esta nova abordagem seja possível, é imprescindível que se conheça e se repense qual o sentido da extensão universitária. Esta surge como um modo alternativo ao capitalismo global, que formará o pensamento e a ressignificação da Universidade, perpassando também pela discussão dos currículos e formação docente, enquanto participa ativamente da construção dos debates sociais. Para além, a extensão universitária não pode ser pautada apenas na prestação de serviços à comunidade, mas também para o desenvolvimento de ações que visem o protagonismo dos diferentes grupos sociais existentes.

Após o desenvolvimento desse trabalho, percebe-se como é imprescindível que a academia assuma uma postura no Ensino e na Pesquisa, que guie o compromisso da universidade, principalmente no que diz respeito a políticas públicas, e que este seja mais um passo alcançado, como já referido anteriormente, para a implementação e, porque não dizer, reconhecimento, da universidade como um espaço socialmente referenciado.

\section{Referências}

BRASIL. Constituição da República Federativa do Brasil. 1988. Disponível em: <http:// www.planalto.gov.br/ccivil_03/Constituicao/Constituicao.htm>. Acesso em: $1^{\mathrm{o}}$ mai. 2016.

BRASIL. Lei Básica da Reforma Universitária. Lei N. ${ }^{\circ} 5.540$ de 1968. Disponível em: <http:// www.planalto.gov.br/ccivil_03/leis/L5540.htm>. Acesso em: $1^{\circ}$ mai. 2016.

BRASIL. MEC - Ministério da Educação e Cultura. Lei de Diretrizes e Bases da Educação Nacional. LDB 9.394/96. Disponível em: <http://portal.mec.gov.br/seesp/arquivos/pdf/lei9394_ldbn1.pdf>. Acesso em: $1^{\circ}$ mai. 2016. 
BRASIL. Plano Nacional de Educação 2014-2024. Lei N. ${ }^{\circ}$ 13.005, de 25 de junho de 2014. Disponível em: <http://www.planalto.gov.br/ccivil_03/_ato2011-2014/2014/lei/113005.htm>. Acesso em: ${ }^{\circ}$ mai. 2016.

BUARQUE, Cristóvão. Um Livro de Perguntas. Rio de Janeiro: Garamond, 2003.

CHAUÍ, Mirela de S. Escritos sobre a universidade. São Paulo: Editora da UNESP, 2001.

FÁVERO, Maria de L. de A. Reflexões sobre Universidade, Pesquisa e Iniciação Científica. In: Revista Brasileira de Política e Administração em Educação, v. 19, n.2, jul/dez. 2003.

FINGER, Almeri P. (Org.) Universidade: Organização, Planejamento e Gestão. Florianópolis: NUPEAU, OEA/UFSC, 1988.

FORPROEX. Fórum de Pró-reitores de Extensão das Universidades Públicas Brasileiras. Org.: Edison José Correa. Extensão Universitária: organização e sistematização. Belo Horizonte: Coopmed, 2007.

MONROE, Paul. História da Educação. São Paulo: Ed. Nacional, 1979.

REZENDE, Antônio M. BIANCHET, Sandra B. Dicionário do Latim Essencial. $2^{\mathrm{a}}$ ed. revista e ampliada. Belo Horizonte: Autêntica, 2014.

ROSSATO, Ricardo. Universidade: nove séculos de História. Passo Fundo: UPF, 2005.

SANTOS, Boaventura de S. A Universidade no Século XXI. $3^{\circ}$ ed. São Paulo: Cortez, 2011.

SANTOS, Marcos Pereira dos. Contributos da extensão universitária brasileira à formação acadêmica docente e discente no século XXI: um debate necessário. Revista Conexão UEPG, v. 6, n. 1, p. 10-15, 2012.

WANDERLEY, Luis Eduardo. O Que é Universidade? São Paulo: Brasiliense, 2003.

Recebido para publicação em 30/10/2016 e aprovado em 20/12/2016.

${ }^{3}$ O discurso hegemônico acadêmico, criticado por Paulo Freire (FREIRE, Paulo. Extensão ou Comunicação. $8^{a}$ ed. Rio de Janeiro: Paz e Terra, 1983), que ainda marca uma concepção assistencialista de Extensão que, entende o estender à sociedade o conhecimento acumulado pela universidade de forma sistêmica. 